\title{
35. EL CONSEJO GENERAL DEL PODER JUDICIAL
}

\author{
MANUEL GERPE LANDÍN \\ Catedrático de Derecho Constitucional
}

Universidad de Barcelona 


\title{
35. EL CONSEJO DEL PODER JUDICIAL
}

\author{
POR \\ MANUEL GERPE LANDÍN \\ Catedrático de Derecho Constitucional \\ Facultad de Derecho. Universidad de Barcelona
}

I. La Nota que presentamos no discute ni la opción del constituyente por la creación del Consejo General del Poder Judicial ni la alta relevancia constitucional que tiene el Consejo como órgano de garantía de la llamada independencia externa de los jueces y magistrados, del Poder Judicial. A ello debe añadirse, lo cual muestra la marginalidad que tiene esta Nota en un debate sobre "Reforma constitucional», que tampoco se discute la redacción que tiene el Consejo en el art. 122 de la Constitución, en la medida que su redacción actual permite integrar las propuestas que sobre su composición y atribuciones aquí se harán.

Tan pacífico punto de partida puede parecer cuanto menos sorprendente si lo contrastamos con la polémica que desde su creación hasta hoy acompaña al Consejo y las incertidumbres que rodean a su posición constitucional, su naturaleza jurídica, su composición y sus atribuciones. Aunque la conflictividad responde a diversas causas, si nos limitamos a su efecto normativo la responsabilidad no puede encontrarse en la redacción del Texto constitucional si no en los intérpretes del mismo especialmente en el momento de su desarrollo legislativo. En otras palabras, los problemas normativos que hoy afectan al Consejo están en su regulación por la Ley Orgánica del Poder Judicial y no en el art. 122 de la Constitución. (Como antes estaban en la Ley Orgánica del Consejo General del Poder Judicial [1980]).

A pesar de nuestro punto de partida y justificado exclusivamente por motivaciones que potencien la seguridad jurídica, dado el tamaño actual de la polémica y la incertidumbre, se sostendrá la conveniencia de 
que la Constitución introduzca mayor fijación de su contenido tanto en lo que afecta a la composición como a las atribuciones del Consejo. Antes de concretarlas, parece oportuno una breve referencia a la polémica.

II. La doctrina coincide en señalas que el CGPJ es uno de los órganos más polémicos de cuantos prevé la Constitución. A ello habría que añadir, si acudimos a las experiencias del derecho comparado asimilables a la española, que los problemas no son menores en Italia (baste recordar la Comisión Presidencial sobre la materia presidida por Livio Paladin y que presentó su Informe en 1991), en Portugal (el Consejo ha estado afectado ya por la reforma constitucional), o en Francia (donde con insistencia se va reforzando la necesidad de la reforma constitucional).

Algunas de las expresiones de la situación española son:

a) Existencia de dos regulaciones legislativas: LOCGPJ (1980) y LOPJ (1985). Aunque la afirmación requeriría mayores matizaciones, se puede sostener que cada Ley configura un "modelo" de Consejo, dadas sus notables diferencias tanto en lo que afecta a su composición como a sus atribuciones.

b) Conflictos del Consejo con las Cortes Generales y con el Gobierno. Con las primeras tiene su momento álgido durante la elaboración de la LOPJ (conflictos de atribuciones ante el Tribunal Constitucional) pero se mantienen de forma latente las diferencias en el momento de deliberación anual de la Memoria presentada por el Consejo. Con el Gobierno el conflicto se remonta ya a la Primera Memoria del Consejo (1981), donde se defiende de forma abierta una concepción del Consejo como «órgano de gobierno políticon del Poder Judicial y una concepción muy expansiva de sus atribuciones en relación con la administración de justicia; lógica de enfrentamiento que se irá acentuando durante el mandato del Primer Consejo, se irá mitigando posteriormente pero no puede considerarse -a pesar de la acentuación de la colaboración con el Ministerio de Justicia- totalmente superada.

c) En la relación del Consejo con la Judicatura, con sus gobernadores, $y$, de forma especial, con las Asociaciones Profesionales de Jueces y Magistrados. La aquiescencia mayoritaria a la política del Primer Consejo, apoyado por la APM y por la implícita consideración de que es un órgano de autogobierno judicial, únicamente es ensombrecida por leves críticas de otros sectores judiciales minoritarios a su escasa incidencia en la 
administración del personal de la judicatura y al funcionamiento de los juzgados y tribunales.

Una situación que variará notablemente en relación con el Segundo Consejo, que recogerá las críticas de la APM que en sus variantes más radicales considerará al Consejo como simple "jefatura de personal colegiada" o como "órgano inútil». Críticas que sería oportuno valorar a partir de las Sentencias del Tribunal Supremo donde se controlan los actos del Consejo.

d) Confusión también en la opinión pública y en los medios de comunicación, donde se denota con suma frecuencia la asimetría entre lo que se cree que puede hacer el Consejo y lo que realmente le compete. Buena prueba de ello es la notable frecuencia con la que se reclaman intervenciones del Consejo en aspectos que, por su naturaleza jurisdiccional, le son ajenos.

e) No es más pacífica la situación en la doctrina: de las primeras posiciones eminentemente abstractas y maximalistas, se ha pasado a las seguidistas de la doctrina del Tribunal Constitucional y legalistas. Unas y otras tienen en común el marginar de su análisis el Texto constitucional, las primeras casi totalmente y las segundas por falta de atención a las singularidades interpretativas que requiere el Consejo.

Se han dicho tantas cosas y tan dispares que sería fácil considerar que cualquier propuesta interpretativa es razonable: el abanico va desde considerar al Consejo como vértice del Poder Judicial, órgano político al que corresponde determinar la política judicial y únicamente responsable ante el Parlamento, a considerarlo un mero órgano administrativo.

Intentando cuanto menos no aumentar la confusión, parece oportuno, antes de hacer las propuestas concretas, indicar los presupuestos constitucionales de las mismas.

018. La determinación de la posición constitucional del Consejo debe hacerse desde los presupuestos siguientes:

a) La Constitución mantiene la definición funcional del Poder Judicial y, en consecuencia, la concepción atomizada o pluralista del mismo. El ejercicio de la potestad jurisdiccional, juzgar y hacer ejecutar lo juzgado, es lo que define al Poder Judicial, siendo sus únicos titulares los jueces y magistrados actuando en Juzgados y Tribunales. 
La primera consecuencia de tal presupuesto es que el CGPJ no forma parte del Poder Judicial, aunque tenga como destinatarios de su gobierno a los Jueces y Magistrados. A pesar de ello, no puede negarse que el CGPJ refuerza la «imagen» de unidad orgánica del Poder Judicial y de su autonomía externa en relación con otras instituciones del Estado, desde la que pueden justificarse en favor del Consejo de funciones representativas de la organización o de representación procesal de los jueces (sustitución procesal) en conflictos de atribuciones.

b) Desde la garantía de la independencia judicial, que tiene como únicos titulares a los jueces uti singuli, no cabe deducir predeterminaciones constitucionales sobre el Gobierno del Poder Judicial. El contenido de la independencia es que los Jueces en el ejercicio de la jurisdicción no están sujetos a órdenes o instrucciones de nadie: están sometidos única y exclusivamente al ordenamiento jurídico y al razonamiento jurídico. La independencia se garantiza frente a todos, y por tanto también frente al Consejo.

La única deducción necesaria desde el principio de independencia es el gobierno por la Ley de la Judicatura; a partir de aquí, y como exterioriza el derecho comparado, todo se relativiza. Insistir en la rigurosa reserva de ley y en que tal ley sea extensa y densa no es cuestión menor en este debate.

c) Si la independencia (jurídica) de los jueces no prejuzga soluciones sobre la organización judicial, la cuestión varía notablemente al tener que conjugarse la determinación de la política judicial con el principio democrático, que requiere que tal competencia recaiga en órganos representativos y responsables políticamente.

La falta de instrumentos para compatibilizar independencia judicial y responsabilidad política está en el origen de la definición funcional del Poder Judicial y el traslado de las decisiones no jurisdiccionales al Ejecutivo, que se responsabiliza políticamente de las mismas ante el Parlamento.

Tal situación impide ciertamente fórmulas de autogobierno judicial en sentido estricto, pero no impide que en abstracto puedan trasladarse tales decisiones a un órgano autónomo y responsable ante el Parlamento. Pero tal situación, defendida por el Primer Consejo, no puede deducirse de la Constitución, tanto si atendemos a las competencias que fija como propias del Gobierno como si atendemos a la composición y atribuciones que otorga al Consejo.

Sin embargo, afirmar que la determinación de la política judicial (in- 
cluida la presupuestaria) corresponden al Gobierno y a las Cortes Generales, ello no excluye reconocer - desde el ámbito funcional que la Constitución de forma expresa reserva al Consejo-que éste debe desarrollar una función coadyuvante, eminentemente consultiva, en la determinación de la política judicial.

d) Si del ámbito político-legislativo (sustantivo, procesal y presupuestario) descendemos al de gobierno y administración del Estatuto legal de los jueces y magistrados es donde nos vamos a encontrar con las facultades decisorias que la Constitución atribuye al Consejo.

De nuevo conviene insistir que ni desde los principios que configuran la forma de Estado ni desde la independencia judicial cabe deducir predeterminaciones sobre las atribuciones anteriores. Únicamente razones de oportunidad, profundamente justificadas en una prolongada experiencia histórica de presión del Gobierno sobre los Jueces por medio de las técnicas de aplicación del Estatuto legal, justifican la solución adoptada. Se parte de la presunción que trasladando tales atribuciones a un órgano autónomo y de composición técnica se garantiza mejor la independencia judicial, como elemento esencial de la tutela judicial efectiva, que dejando tales atribuciones en el Ministerio de Justicia.

Sin predeterminaciones necesarias desde los principios constitucionales la conclusión parece contundente: el Consejo tiene la composición y las atribuciones que la Constitución de forma expresa determina, sin que puedan deducirse poderes implícitos ni de la autonomía del Poder Judicial ni de la independencia judicial.

Tal conclusión ciertamente nos aproxima a las que anteriormente hemos denominado posiciones seguidistas y legalistas, la diferencia se encuentra en que consideramos que al artículo 122 debe ser interpretado sistemáticamente y que la propuesta sobre su composición y funciones debe garantizar: la funcionalidad del órgano, su autonomía institucional, la eficacia en el cumplimiento de sus funciones, y el control sobre sus actuaciones.

Desde tales criterios, se hace la interpretación del art. 122, y es desde ellos desde los que se sugieren leves modificaciones a su contenido.

IV. Acerca de la composición dos temas parecen destacables: A) La designación de los 12 vocales judiciales, y $B$ ) Los criterios de elegibilidad de los Vocales designados por las Cámaras. 
A) La propuesta que se defiende es que los Vocales designados entre jueces y magistrados sean elegidos por la propia Judicatura. Aunque la parlamentarización total de la designación ha sido legitimada por el Tribunal Constitucional, se considera que existen razones suficientes para sostener la vía electiva por los jueces y magistrados. Algunas de ellas serían:

a) Decir, como hace el Tribunal Constitucional, que la autonomía institucional del órgano no depende de la forma de propuesta si no del estatuto o posición jurídica en que se sitúa a los Vocales es una argumentación que puede admitirse siempre que maticemos que la opción tiene importantes efectos, ya que de la forma de propuesta depende la ubicación política del Consejo: no tendrá el mismo peso político un Consejo designado por el Parlamento totalmente que otro, cuya mayoría de miembros, es designado directamente por los jueces $y$, por tanto, por las Asociaciones de Jueces, tras un proceso electoral en el que se han expresado diferentes concepciones sobre la Administración de Justicia.

b) La misma argumentación político-institucional debe atender a que si se admite, como hace el Tribunal Constitucional, que la funcionalidad del Consejo es desapoderar al Gobierno de aquellas atribuciones que pueden presionar sobre la independencia judicial, la lógica de la parlamentarización lleva al probable riesgo, cuanto menos en el origen, de que la mayoría gubernamental designe también a la mayoría de Vocales del Consejo.

c) Admitiendo que el Consejo no es un órgano de autogobierno judicial tampoco es un Comisionado de las Cortes Generales, y por tanto, si la composición pretende garantizar la presencia dentro del Consejo de las diferentes visiones técnicas sobre el mundo de la Justicia, y en entre ellas de forma mayoritaria a la de los jueces y magistrados, entender que las Cortes pueden dar un reflejo más fiel de tales visiones que los propios jueces, sólo puede ser expresión de una concepción de la democracia poco atenta al pluralismo o de despotismo ilustrado (del viejo jacobinismo de Azaña, que también dudaba que los Jueces supieran mantener la prevalencia "del espíritu público nacional»); en cualquier caso implica un prejuicio inaceptable, y no compensable por el riesgo de corporativismo, ya que éste debe equilibrarse con el de politización partidista (no afectando este último a los jueces dada la prohibición de pertenencia a partidos políticos).

d) No puede desconocerse, aunque no sea un órgano de autogobierno, que el Consejo gestiona intereses colectivos de la Judicatura y que 
la opinión pública hace un juicio sobre la actuación del Consejo que afecta a la Carrera sin que ésta tenga representación.

e) A la misma conclusión conduce considerar que el gobierno de los jueces debe respetar los principios del ordenamiento constitucional, $y$ de forma singular el de participación de los jueces en cuanto tales en el mismo. Negarla es, además, renunciar, aunque sea indirectamente, a un canal interno de democratización de la Carrera judicial, de romper con el tradicional aislamiento de los jueces, y debilitar la legitimación del Consejo ante sus gobernados, lo que necesariamente tendrá consecuencias sobre la legitimación del Consejo y sobre sus funciones.

B) En relación con los ocho Vocales propuestos por el Parlamento, entre abogados y juristas, todos ellos de reconocida competencia y con más de quince años de ejercicio en su profesión, debe destacarse que el control de los requisitos $y$ de la condición de jurista es de notable importancia, a pesar de ello no parece que un Texto constitucional pueda ir más allá en su regulación que lo establecido en el art. 122.

Debe ser la Ley, el Reglamento parlamentario, y el arraigo de los criterios técnicos sobre los partidistas en el momento de la designación los que deben dar las soluciones a este espinoso tema.

V. Una interpretación sistemática del art. 122, permite hacer las consideraciones siguientes sobre su ámbito funcional:

a) Como órgano autónomo deben reconocérsele las atribuciones que garanticen tal autonomía funcional.

b) La delimitación, ad exemplum, de sus facultades en relación con la Judicatura permite considerar que pueda en el ámbito del Consejo todo lo que afecta a la relación orgánica de los jueces y magistrados (no la relación de servicio). Aquí, y en relación con la aplicación del Estatuto legal del personal jurisdicente, se sitúan las facultades decisorias del Consejo.

c) La atribución de la función inspectora, autónoma de la disciplinaria, implica necesariamente reconocer al Consejo: a) Funciones en relación con el funcionamiento de los juzgados y tribunales que, aunque quieran limitarse al personal judicial, no puede excluir cuestiones orgánicas, procesales, materiales y del personal al servicio de la Administración de 
justicia; $b$ ) Hacer funcional el monopolio que tiene el Consejo sobre la Inspección, sobre la información, requiere dotar al Consejo de instrumentos relacionales con los órganos a los que corresponde la decisión sobre tales materias (Memorias, Informes, Propuestas, Comisiones mixtas con órganos centrales y autonómicos).

d) Su naturaleza de órgano autónomo, su composición técnica y con presencia de visiones diferenciadas sobre la Administración de Justicia, junto a la información que monopoliza sobre el funcionamiento de la misma le hacen un órgano especialmente adecuado para Informar todas las normas generales que afecten a la Administración de Justicia.

e) Como órgano instrumental para garantizar la independencia judicial y como reforzador de la imagen de autonomía funcional del Poder Judicial frente al exterior, deben reconocerse en favor del Consejo facultades de representación procesal en defensa de la independencia de los jueces y magistrados y de sustitución procesal de los mismos en los conflictos de atribuciones.

La concreción de tal concepción funcional no consideramos que requiera ser realizada por el Texto Constitucional, debe ser la LOPJ la que la desarrolle.

Sin embargo, la atención a los desarrollos legislativos - LOCGPJ y LOPJ- muestra que tal concepción no está asentada. La primera regulación es más fiel a la misma, aunque incluye excesos problemáticos, y la segunda se hace con criterios claramente restrictivos. Tomando como referencia la vigente LOPJ, consideramos que su adecuación al modelo constitucional que se sostiene requeriria añadir a sus actuales atribuciones las siguientes:

- Elaborar su Proyecto de Presupuesto, en los mismos términos que el Tribunal Constitucional.

- Atribuir al Consejo la dirección del proceso de selección de Jueces y Magistrados.

- Atribuir al Consejo la dirección de la Escuela Judicial.

- Reconocer al Consejo la representación procesal de los Jueces en conflictos de atribuciones (sustitución procesal). 
- Regular con generosidad la facultad de Informe del Consejo sobre normas generales que afecten a la Administración de Justicia.

- Establecer canales para que el Consejo pueda hacer propuestas en materias de funcionamiento de la Administración de Justicia.

Tal ámbito de atribuciones consideramos que quedaría garantizado: a) Incluyendo dentro del Texto constitucional, junto a las atribuciones que enumera ad exemplum, las de "selección" y "formación y perfeccionamiento"; la primera no implica, obviamente, que el Consejo la monopolice pero sí que la dirija; la segunda, siempre reconocida como exclusiva, pretenderia realzar que una función esencial del Consejo es garantizar la cualificación profesional de los jueces y magistrados, como garantía nuclear de la independencia judical; b) Su representación en conflictos de atribuciones requeriría modificar la LOTC, lo que permitiría hacer funcional un procedimiento actualmente inservible.

VI. Abro este apígrafe únicamente para justificar que los problemas que rodean al Consejo no son únicamente los tratados (composición y atribuciones). Junto a ellos, y de notable entidad sustantiva, están los de organización de la función de gobierno y el de control de los actos del Consejo. 